\title{
MuseOlOGI OCH KRISHANTERING
}

Från att tillsammans med skolor, arkiv och bibliotek ha varit samhällsminnets grundstenar har de svenska museerna transformerats till 'museibranschen'. Och branschen har hamnat i kris. Dess innebörd beskrivs i detta nummer av Kerstin Smeds och Gjertrud Sater. I branschtidningen (sic!) Svenska Museer 2004/1 ställer Gunilla Cedrenius, erfaren museikännare, krisfrågan: "Vem vågar på allvar pröva sitt museum från grunden och inte lappa och laga en konstruktion som visar tydliga spår av bräcklighet?".

Inom museologin framstår alltmer musealisera (=människans behov att ur den omgivande fysiska verkligheten utvälja och samla minnesvärda element för att bevara) som nyckelordet. Museer och kulturmiljövård har att på samhällets uppdrag tjäna som medium för musealiseringen av gemensamma materiella kulturminnen. PRO MEMORIA vore därför den adekvata överskriften för alla museala institutioner i deras egenskap av offentliga förvaltare av minnesvärden.

Minnesvärdet definieras och dokumenteras i musealiseringens inledningsfas. Det exponeras när det i förmedlingsfasen tolkas, dvs. översätts i nuets språk och perspektiveras inom dess förståelseramar: minnesvärdet förvandlas till samtidsvärde.

Musealiseringens långsiktiga mål berördes i en föreläsning av professor Barbara Kirshenblatt-Gimblett för ett par år sedan. Hon använde begreppet informativ museologi för museernas traditionella minneshantering, som i princip byggt på att institutionellt traderade minnesvärden godtagits, och introducerade performativ museologi för en ny användning av samlingarna i ett ifrågasättande, kritiskt, förhållningssätt till den historiekonstruktion som en tidigare musealisering medverkat i. När minnesinstitutioner samverkar med exempelvis konstnärer och med sin publik ser hon en utväg som ger transparens åt minnesarbetet och upprättelse åt trovärdigheten. Riksutställningars Svåra saker var för henne en idealmodell - den gav genomskinlighet åt det antikvariska minnesuppdraget.

Med begreppsparet informativ/performativ gav Kirshenblatt-Gimblett musealiseringen operativ tillspetsning. Flera andra 'museologier' kan tänkas. Ekomuseologi skymtade för några år sedan som en musealisering av landskapsrummet. Narrativ museologi skulle inriktas på berättelser (så t.ex. i Mölndals museum, där i det öppna magasinet minnen som föremålen väcker hos besökarna skrivs ner). Signifikativt är att ICOM för sin kommande generalkonferens valt temat 'Museums and intangible 
heritage'. Historisk museologi vore särskilt viktig för museernas självkännedom (detta exemplifierade Kirshenblatt-Gimblett med bl.a. Hallwylska museet i Stockholm och Teylers museum i Haarlem).

Vi får med ens en palett av alternativa museologier som möjliga riktningsgivare när det för minnesinstitutionerna gäller att överleva sina kriser. Med hjälp av den numera omfattande museologiska litteraturens rika förråd av fallbeskrivningar och arbetsmodeller samt med en analys av samlingarnas art och det omgivande samhällets minne och levande liv går sannolikt krislösningar att finna.

Det performativa, i sitt samhälle intervenerande museet är lätt igenkännligt i numrets klassiker där Marc Maure påminner om John Kinard och Anacostia museum i Washington D.C.

Det traditionella informativa kunskapsmuseet föryngrat med faktarum, med öppna databaser där samlingar och utställningar finns virtuellt tillgängliga samt med extensiva skolprogram, har valt det kanske vanligaste sättet att anpassa museimediet till samtidens efterfrågan på historisk kunskap. Härtill anknyter det samarbete i ett nytt nätverk som Clara Camacho beskriver från Portugal och det arbetssätt som Tomas Johansson utvecklade.

Det narrativa museet som samlar de berättelser som ger historisk mening och inte bara estetisk - aura åt samlingarnas föremål blir allt mer uppmärksammat. Därom vittnar Bente Gundestrups uppsats om den berömda danska Kungliga Konstkammaren och Eckhouts målningar.

Ekomuseologin riktar sig mot omvärldens miljöminne med naturhistorien helt eller delvis dold av mer och mindre mäktiga kulturlager. Mot verkligheten utanför museiväggarna vänder sig Lähtesmäkis och Liimatainens uppsatser.

Den historiska museologins kritiska potential ger Eva Persson ett exempel på med sin rapport från etnografiska museet i Neuchâtel. När Marc Maure skriver om Artur Hazelius och hans samtida Bernhard Olsen i Danmark och Anders Sandvig i Norge belyser han den i museihistorien ständigt återkommande antagonismen mellan uppvisning och iscensättning i museernas förhållningssätt till sina kulturminnen.

$$
\text { Per-Uno Agren }
$$

PS 1. Museibranschen blev en gångbar beteckning i mitten av 1990-talet. Men det är ett ödesdigert ordval med sin förföriska kommersiella konnotation. Termen avvisas av danska och norska museer.

PS 2. Barbara Kirshenblatt-Gimbletts föreläsning finns tryckt i Museum 2000. Confirmation or Challenge. Svenska ICOM, Svenska Museiföreningen, Riksutställningar. Stockholm 2001. 